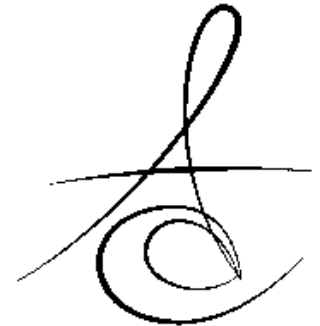

Makale Kodu/Article code: 2532

Makale Gönderilme tarihi: 28.12.2015

Kabul Tarihi: 23.03.2016

\title{
DOĞAL DİŞLİ BİREYLERDE ALTIN ORANIN DEĞERLENDİRİLMESİ ${ }^{*}$
}

\section{THE EVALUATION OF GOLDEN PROPORTION IN PERSONS WITH NATURAL DENTITIONS ${ }^{*}$}

Yrd. Doç. Dr. Hatice ÖZDEMİR*

\author{
Prof. Dr. Funda BAYINDIR*
}

\section{öz}

Amaç: "Altın oran" uzun yıllardır diş hekimliğinde kullanılan bir orandır. Özellikle, anterior bölgede yapılan restorasyonlarda estetik sonuç elde etmek için bu oran esas alınmaktadır. Bu çalışmanın amacı, diş hekimliği fakültesinde eğitim gören öğrencilerin maksiller ön dişlerin arasındaki oranların altın oranla ilişkisini değerlendirmektir.

Gereç ve Yöntem: Bu çalışmada Atatürk Üniversitesi Diş Hekimliği Fakültesinde eğitim gören 85 öğrencinin üst çenelerinden ölçü alındı. Ölçülere alçı dökülerek model elde edildi. Altın oran için gerekli ölçümler bu modeller üzerinden yapıldı. Maksiller ön dişlerdeki oranların altın oranla karşılaştırılması yapıldı.

Bulgular: Elde edilen veriler t-testi ile analiz edildi. Analiz sonucu elde edilen verilerin $(1,249)$ altın orandan $(1,618)$ önemli derecede farklı olduğu bulundu. $(p<0,05)$

Sonuç: Elde ettiğimiz verilerin altın orandan farklı olması bu bireylerin estetik bir diş yapısına sahip olmadığı anlamına gelmemektedir. Yüzü oluşturan parçaların birlikte değerlendirilmesi daha önemlidir.

Anahtar Kelimeler: Altın oran, doğal dişli birey, estetik

\section{GİRİş}

Çalışmaların önemli bir kısmı, hastaların estetik görünüme fonksiyondan daha çok önem verdikleri için anterior diş kayıplarında kayıp dişlerin yerine konulmasına daha çok öncelik verdiklerini göstermektedir. ${ }^{1-5}$ Estetik bölgedeki dişlerin başarılı bir şekilde restore edilmesinin sonucunda hastanın kendine özgüveni ve yaşam kalitesi artar. $^{6}$ Ayrıca dento-fasial bölgedeki çekiciliğin bireyin psiko-sosyal durumunu olumlu

\section{ABSTRACT}

Aim: "Golden proportion" is a proportion used in dentistry for long years. Especially, this proportion use for anterior restorations to obtain esthetic results. The aim of this study, the evaluation of the relationship between golden proportion and the proportion of maxiller anterior teeth in students of dentistry.

Material and Methods: In this study, taken impression from maxilla of 85-students educated in Atatürk University, Faculty of Dentistry. The model were made by pouring dental stone. Necessary measurements for golden proportion were made on these models. The proportions of maxiller teeth were compared with golden proportions.

Results: The data were analyzed with t-test. The results $(1,249)$ are found significantly different from golden proportion $(1,618)$. $(p<0,05)$

Conclusions: The difference between the results we found and golden proportion isn't meaning these people haven't got esthetic teeth structure. It is most important to evaluate the parts together created the face.

Key words: Golden Proportion, person with natural dentition, esthetic

yönden etkilediği ispatlanmış bir gerçektir. ${ }^{7}$ Estetik diş hekimliğinin önemli bir görevi, anterior dişlerin restorasyonu ya da yeniden yapımı sırasında maksiler anterior dişlerin genişlikleri arasında boyutsal bir uyum oluşturmaktır. "Altın oran" kavramı, gülüş dizaynında önemli bir parametresi olarak tanımlanmaktadır., 8 Aristo MÖ 4.yy gibi erken bir dönemde estetikte oranların önemine dikkat çekmiştir. Altın oran Pisagor tarafından MÖ 6.yy' da ve kısa bir süre sonrada Alman geometrici Öklid tarafından tarif edilmiştir. Bununla

\footnotetext{
*Atatürk Üniversitesi Diş Hekimliği Fakültesi Protetik i AD

F Bu çalışmamız, Erzurumda düzenlenen 5. Uluslararası TPİD Palandöken Kış

Sempozyumunda poster olarak sunulmuştur.
} 
birlikte, Almanlardan daha uzun süre önce Mısırlılar altın sayısını $(\phi) 1.618$ ve altın dikdörtgenin genişliğinin uzunluğuna oranını $1.6\left(\phi^{\prime}\right)$ olarak bulup ve düzenlemişlerdir. ${ }^{10-15}$ (Şekil.1)

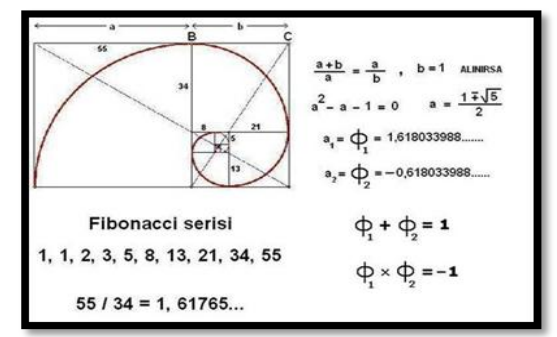

Şekil 1. Altın oranın altın dikdörtgene göre hesaplanması

Altın oran antik Alman mimarisinde Parthenon' un dizaynında ve ayrıca da Vinci insan anatomisinin klasik çizimlerinde kullanılmıştır. ${ }^{16}$ Ricket $^{17}$ etkili yüzün çeşitli elementleri arasındaki oranı değerlendirmek ve kanıtlamak için bir altın oran pergeli icat etmiştir.

Araştırmalarda, estetik bir restorasyon oluşturmak için araştırıcıların çoğu orta hattan itibaren anterior dişler arasındaki ilişkiyi tarif etmek için matematiksel yada geometrik oranların kullanımını tavsiye etmişlerdir. ${ }^{18}$ Lombardi $^{19}$ altın oranın diş hekimliğinde kullanılmasını öneren ilk kişidir. Lombardi diş boyutunu belirlemede altın oran kullanımının çok güçlü bir faktör olduğunu da belirtmiştir. Ayrıca, optimize bir dento-fasial kompozisyon sağlayan tekrarlanan oran kavramının lateral dişin santral dişe göre genişliği ve köpek dişinin lateral dişe göre genişliğinde bulunmasının önemine dikkat çekmektedir. ${ }^{19}$ Levin $^{8}$ labialden bakıldığında anterior dişlerin genişliğinin başarılı bir şekilde sağlanabilmesi için altın oranın kullanımını tavsiye etmiştir.

Üst ön dişlerin üst dudak çizgisinden 2-3 mm uzun olması estetik yönden ideal olarak kabul edilir. ${ }^{20}$ Genç insanlarda ağız hafif açık iken maksiler dişlerin insizal kenarının yaklaşık 3.5 mm' lik bir bölümü görünür, mandibular dişler ise belirgin olarak gözlenebilir. Üst ön dişlerin dudak ilişkileri kişinin genç ve yaşı görünümünü etkileyen faktörler arasındadır. Yaş ilerledikçe kasların gerginliği azalmaktadır. Bu durum maksiller kesicilerin görünürlüğünü azaltırken mandibular kesicileri gittikçe daha görünür hale getirmektedir. Üst santral dişlerin gülümseyişte ortaya çıkmaması kişiye yaşı bir görünüm verir. ${ }^{21}$ Gülme esnasında dişlerin görünürlülüğü hesaplandığında erkeklerde $1.91 \mathrm{~mm}$, kadınlarda $3.4 \mathrm{~mm}$ olduğu gözlemlenmiştir. ${ }^{22}$

Dişlerin uzunluğu kadar genişliği de önemlidir. Uzunluk ve genişliğin orantılı olması gerekli bir faktördür. Özellikle diastema kapatmada bu oranların iyi ayarlanmaması hastaya kötü bir görünüm sağlayacaktır. Alt 6 ön dişin M-D boyutları toplamı, üst 6 ön dişin M-D boyutları toplamının 4/5' i kadardır. Önemli bir nokta da kesici ve köpek dişlerinin servikal genişlikleri genellikle birbirine eşittir. Köpek dişlerinde olduğu kadar santral dişler arası büyüklük farkı da göze hoş görünmeyen tablolar ortaya çıkarır. Bu durum özellikle yüksek gülme hattına sahip kişilerde göze batar. ${ }^{23}$

Dişlerin oranları denildiği zaman iki durum anlaşılır. Birincisi her bir dişin kendi uzunluğu ile genişliğinin oranı, ikincisi ise dişlerin birbirleriyle olan oranlarıdır. Güzel bir görünüm elde edebilmek için bu iki oranın da uyumlu olması gerekir. ${ }^{24,25}$ Diş oranları hakkında bazı teoriler ortaya atılmıştır. Dişin genişliğinin yüksekliğine oranı; ön dişler için 0.7/1 dir. (Şekil.2) Bu oran altın orana çok yakın bir orandır.

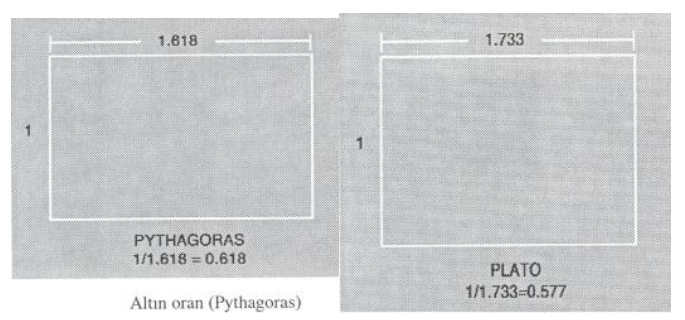

Şekil 2. Pisagor ve Plato oranları

Dişlerdeki altın oran, dişlere önden bakıldığında ön santral kesici dişin genişliğinin yan kesici dişe oranı $1.618^{\prime}$ dir. Yan kesici dişin genişliğinin köpek dişine oranı yine $1.618^{\prime}$ dir. Bunun yanı sıra santral diş 1.618, lateral diş 1.0, köpek dişi ise 0.618 oranında görünürlüğe sahiptir. ${ }^{26}$ (Şekil.3)

$\mathrm{Bu}$ çalışmanın amacl, doğal dişli bireylerde maksiller ön dişlerin arasındaki oranların altın oranla ilişkisini değerlendirmektir.

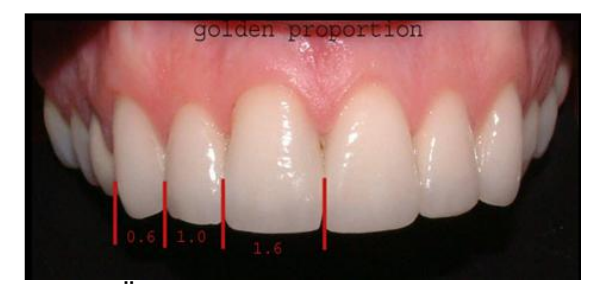

Şekil 3. Ön grup dişlerde görülen altın oranlar

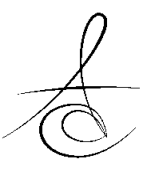




\section{MATERYAL VE METHOD}

Bu çalışmada 3. molar diş eksikliği hariç diş eksikliği olmayan, ön grup dişlerine herhangi bir restorasyon yapılmamış olan Atatürk Üniversitesi Diş Hekimliği Fakültesinde eğitim gören 85 öğrencinin maksiller dişlerindeki oranların altın oranla karşılaştırması yapıldı. Çalışmaya dahil edilecek öğrenciler seçilirken, ortodontik tedavi görüp görmedikleri sorularak ortodontik tedavi görenler çalışmaya dahil edilmedi. Ayrıca, ön grup dişlerinde restorasyon veya dolgu olan, ön grup dişleri travmaya uğramış ve maksillo-fasiyal cerrahi operasyonu geçirmiş öğrencilerde çalışmanın dışında bırakıldı. Öğrencilerin yaş aralığı 21-24 arasında değişmektedir.

Çalışmaya dahil edilen öğrencilerin üst çenelerinden ağızlarına uygun büyüklükte metal ölçü kaşıkları kullanılarak irreversible hidrokolloid ölçü maddesiyle ölçüleri alındı. Ölçü ağızdan çıkarılarak ağız sıvıları uzaklaştırıldıktan sonra hemen alçı dökülerek modeller elde edildi.

* Elde edilen modeller üzerinde yapılan ölçümler;
A: Üst orta kesici diş uzunluğu
B: Üst orta kesici diş genişliği
C: Üst yan kesici diş genişliği
D: Üst köpek dişi genişliği

* Elde edilen ölçümler üzerinde yapılan oranlamalar;

A/B: Üst orta kesici dişin uzunluğunun genişliğine oranı

B/C: Üst orta kesici dişin genişliğinin yan kesici dişin genişliğine oranı

C/D: Üst yan kesici dişin genişliğinin köpek dişinin genişliğine oranı

Ölçümler sırasında ortodontik pergel ve elektronik kumpas kullanıldı. (Şekil.4) Toplamda 340 diş ölçümü ve 255 diş oranlaması kaydedildi. Belirlenen ölçümler ve oranlamalar yapıldıktan sonra elde edilen sayısal sonuçların altın oranla karşılaştırması yapıldı. Verilerin istatistiksel analizinde mevcut değerlerden olan farklıığı belirlemek için t-testi yapıldı. Altın orandan sapma olup olmadığı, sapma varsa ne kadar olduğu değerlendirildi.

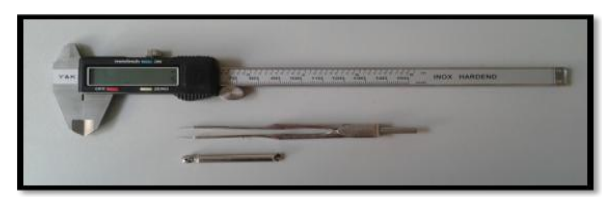

Şekil 4. Çalışmada kullanılan elektronik kumpas ve ortodontik pergel

\section{BULGULAR}

Elde edilen ölçümlere ve ölçümlerin oranlamalarına ait ortalama ve standart sapma değerleri Tablo.1' de verilmiştir. Ölçümlerin oranlamalarına ait elde edilen değerler literatürlerde kabul edilen altın oran değerlerinden küçük bulunmuştur.

Tablo 1. Oranlamalara ait ortalama ve standart sapma değerleri

\begin{tabular}{|c|c|c|c|}
\cline { 2 - 4 } \multicolumn{1}{c|}{} & & Ortalama & Standart Sapma \\
\hline $\mathrm{A}$ & 85 & 10.192 & 0.858 \\
\hline $\mathrm{B}$ & 85 & 9.141 & 0.445 \\
\hline $\mathrm{C}$ & 85 & 7.343 & 0.527 \\
\hline $\mathrm{D}$ & 85 & 8.411 & 0.362 \\
\hline $\mathrm{A} / \mathrm{B}$ & 85 & 1.117 & 0.955 \\
\hline $\mathrm{B} / \mathrm{C}$ & 85 & 1.249 & 0.778 \\
\hline $\mathrm{C} / \mathrm{D}$ & 85 & 0.873 & 0.513 \\
\hline
\end{tabular}

Oranlamalar sonucu elde edilen değerlerin mevcut altın oran değerlerinden farklılı̆ının olup olmadığını belirlemek için t-testi yapıldı. t-testi sonuçları Tablo.2' de verilmiştir. Analiz sonucuna göre, elde edilen değerlerin altın oran değerlerinden göstermiş olduğu farklılıklar istatistiksel olarak önemli bulunmuştur $(p<0.05)$

Tablo2. t-testi sonuçları

\begin{tabular}{|c|c|c|c|c|c|c|}
\hline & \multicolumn{6}{|c|}{ Test değeri= 1.618} \\
\hline & \multirow[b]{2}{*}{$\mathrm{T}$} & \multirow[b]{2}{*}{$\mathrm{df}$} & \multirow[b]{2}{*}{$\mathrm{P}$} & \multirow[b]{2}{*}{$\begin{array}{l}\text { Ort. } \\
\text { farklılık }\end{array}$} & \multicolumn{2}{|c|}{$\begin{array}{l}\text { Farklılığın \% } 95 \\
\text { güven aralığı }\end{array}$} \\
\hline & & & & & $\begin{array}{l}\text { En } \\
\text { düşük } \\
\text { değer }\end{array}$ & $\begin{array}{l}\text { En } \\
\text { büyük } \\
\text { değer }\end{array}$ \\
\hline$A / B$ & -48.424 & 84 & 0.000 & -.502 & -.522 & -.481 \\
\hline $\mathrm{B} / \mathrm{C}$ & -43.719 & 84 & 0.000 & -.369 & -.386 & -.352 \\
\hline$C / D$ & -133.796 & 84 & 0.000 & -.745 & -.756 & -.734 \\
\hline
\end{tabular}

\section{TARTIŞMA}

Uyumlu bir anterior diş dizisinde en etkili faktörler maksiller santral dişlerin ebat, şekil ve konumlarıdır. Hoş bir diş dizisinde orantı anahtardır ve ister zayıf ister güçlü olsun hastanın yüzündeki karakteristik özellikler ile uyum içinde olmalıdır. Güzel görünmesi için maksiller santral kesici dişler yüz morfolojisi ile uyum içerisinde olmalı ve diş arkı ile devamlılık göstermelidir. ${ }^{27}$ Nikgoo ve ark. ${ }^{28}$ maksiller santral ve lateral dişlerin estetik bir şekilde restore edilebilmesi için altın orandan yararlanılabileceğini bildirmiştir. Yüz ahengini elde etmek için, tüm anterior diş kompozisyonu bütün bir resim gibi ele alınmalı, yüz yapısının diğer eleman- 
ları da bu resmin çerçevesini oluşturmalıdır. Bilerek veya bilmeden, göze hoş görünen orantısal ilişkiler ancak belirli kuralların uygulanması ile yakalanabilir. İki parça arasındaki ahenk ilişkisinde olduğu gibi, güzellik sayısal değerler ile bağlantılıdır. Diş hekimliğinde "altın oran" terimi, diş dizisinin orantıları ile ilgili bir matematik teorisidir. Maksiller dişlerin frontal açıdan düzenlenmesinde baskınlık ve orantının tespit edilmesi için tek matematiksel araç olarak kabul görmektedir. Lombardi $^{19}$ bu denklemi gerçek anlamda dişhekimliğine ilk uyarlayan kişi olmuştur ve Levin ${ }^{8}$ görsel algılama prensiplerini ve dental estetiğe uygulanmalarını geliştirmiştir. Belirli oranların diğerlerinden daha fazla kabul gördüğü ve güzelliğin bu orantılar ile denk hale getirildiği bulunmuştur. Bu kurala göre, eğer her anterior dişin genişliği komşu anterior dişin boyutunun yaklaşık \%60'ı kadar ise, estetik açıdan memnun edici bir sonuç ortaya çıkar. Buna göre, eğer lateral kesici dişin genişliği 1 ise, santral kesici diş 1.618 kez daha geniş ve kanin diş 0.618 kez daha dar olmalıdır. ${ }^{27}$

Kalaivani ve ark. ${ }^{29}$ stomatognatik sistemin ahenginin sağlanması için full-mouth rehabilitas- yonlarda estetik, okluzal ve fonksiyonel parametrelerin tedavi planlamasında dikkate alınması gerektiğini bildirmişlerdir. ${ }^{29}$ Yüz estetiğini değerlendirmede altın oranın gösterdiği önemlilikten dolayı iki değer arasındaki ilişki en ince ayrıntısına kadar araştırımalıdır.

Çalışmamız sonucu elde ettiğimiz verilerin istatistiksel analizi altın orandan önemli derecede farklılıklar olduğunu ve altın oran değerlerinden küçük olduğunu göstermiştir. Yapılan çalışmalarda da birebir altın oranla uyum olmadığı bildirilmiştir. Hasanreisoğlu ve ark. $^{31}$ yaptığı çalışmada, dişlerin boyutlarının birbirlerine oranlanması sonucu elde edilen değerler altın oran' dan farklı bulunmuştur. Condon ve ark. ${ }^{32}$ yaptığı çalışmada da, 18-25 yaş arası 133 öğrenci değerlendirilmiş ve elde edilen değerlerin altın orandan farklı olduğu tespit edilmiştir.

Preston $^{33}$, dental literatürde altın oranın gerçek dışı bir doğası olduğunu bildirmiştir. -Gillen ve ark. ${ }^{34}$ yaptıkları çalışmada altın oran ile değerlendirdikleri diş boyutları arasında zayıf bir ilişki olduğunu tespit etmişlerdir. Rosential ve ark. ${ }^{35}$, altın oranın yalnızca uzun dişlerde aranması gerektiğini bildirmişlerdir. AlMarzok ve ark. ${ }^{36}$ yapmış olduğu çalışmada, değerlendirdikleri bireylerin dişlerinde altın oran olmadığını ve farklı etnik gruplar arasında altın oran açısından önemli bir farklılık olmadığını bildirmişleridir. Koca ve Dinçkal ${ }^{37}$ yaptıkları çalışmada maksiller ve mandibular ön dişlerin oranlarını karşılaştırmış ve elde ettikleri sonuçların bilinen 5/4 oranından istatistiksel olarak önemli derecede farklı olduğunu bildirmişlerdir.

\section{SONUÇ}

Altın oran, estetik ve ideal bir gülüş tasarlanırken dikkate alabilecek oranlardır. Estetik diş hekimliği bu altın oranların hesaplanması ve uygulanması ile daha bilimsel bir platforma yerleşir. Çalışmamızın sonucunda elde ettiğimiz verilere dayanarak değerlendirdiğimiz bireylerin anterior dişler arasında altın oranın tam olarak sağlanmadığını tespit edilmiştir. Ancak, altın oranla uyumlu bir oran olmaması yüz morfolojisi ve dental arktaki diğer dişlerle uyumlu olmadığı anlamına gelmemektedir. Çünkü yüz bir bütündür, tüm parçaların birlikte değerlendirilmesi daha doğru sonuçlar vermektedir. Doğada ise estetik, her zaman altın oran ile kendini göstermez. Çünkü öyle olsaydı, etrafımızı birçok klişe sarmış olacaktı. Bununla birlikte 0.8 ve 0.577 sayıları da estetik olarak algılanmaktadır.

\section{KAYNAKLAR}

1. Elias AC, Sheiham A. The relationship between satisfaction with mouth and number and position of teeth. J Oral Rehabil 1998;25:649-61.

2. Carlson GE, Otterland A, Wennstrom A, Odont D. Patient factors in appreciation of complete dentures. J Prosthet Dent 1967;17:322-9.

3. Seifert I, Langer A. Evaluation of psychologic factors in geriatric denture patients. J Prosthet Dent 1962;12:516-23.

4. Wakabayashi N, Yatabe M, Ali M, Sato M, Nakamura K. The influence of some demographic and clinical variables on psychosomatic traits of patients requesting replacement removable partial dentures. J Oral Rehabil 1998;25:507-12.

5. Zarb GA, Bolender CL, Eckert SE, Jacob RF, Fenton $\mathrm{AH}$, Mericke-stern RM. Prosthodontic treatment for edentulous patients: complete denture and implant-supported prosthesis. St. Louis, Mosby. 2004. p. 195-8.

6. Davis LG, Ashworth PD, Spriggs LS. Psychological effects of aesthetic dental treatment. J Dent 1998;26:547-54.

7. Baydaş S. Yapay ön dişlerde estetik sorunlar.

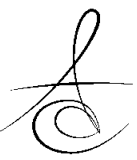


Atatürk Üniv Diş Hek Fak Derg 1996;1:43-50.

8. Levin EI. Dental esthetics and the golden proportion. J Prosthet Dent 1978;40:244-52.

9. Philips RW. Science of Dental Materials. 9. Baskı. WB Saunders Co, Philadelphia. 1991.

10. Beder OE. Esthetics--an enigma. J Prosthet Dent 1971;25:588-91.

11. Anusavice KJ. Phillip's Science of Dental Materials. 10th Baskı. Philadelphia, W.B. Saunders Co., 1996.

12. Mandikos MN, McGivney GP, Davis E, Bush PJ, Carter JM. A comparison of the wear resistance and hardness of indirect composite resins. J Prosthet Dent 2001;85:386-95.

13. Rhan AO, Ivanhoe JR, Plummer KD. Text book of complete dentures. 5th ed., London, Lea\&Febiger. 1993.

14. Diaz-Arnold AM, Dunne JT, Jones AH. Microhardness of provisional fixed prosthodontic materials. J Prosthet Dent 1999;82:525-32.

15. Hirano S, May KB, Wagner WC, Hacker $\mathrm{CH}$. In vitro wear of resin denture teeth. J Prosthet Dent 1998;79:152-6.

16. Rosenstiel SF LM, Fujimoto J. İçinde:Contemporary fixed prosthodontics. 3. Baskı. St. Louis, CV Mosby, 2001. 598-9.

17. Ricketts RE. The divine proportion in facial esthetics. Clin Plast Surg 1982;9:401-42.

18. Ali Fayyad M, Jamani KD, Agrabawi J. Geometric and mathematical proportions and their relations to maxillary anterior teeth. J Contemp Dent Pract 2006;7:62-70.

19. Lombardi RE. Principles of Visual-Perception and Their Clinical Application to Denture Esthetics. J of Prosth Dent 1973;29:358-82.

20. Yamamato MM, Y. Kataoka, S. Special Discussion Fundamental Esthetics countring Techniques for metal ceramic restorations. Quintessence Pub 1990/1991;14:10-81.

21. Vig RG, Brundo GC. The kinetics of anterior tooth display. J Prosthet Dent 1978;39:502-4.

22. CR. R. Fundamentals of Esthetics Chicago. Baskı. Quintessence. 1990-1992:33-7.

23. Çalıkkocaoğlu S. Tam Protezler. 7. Baskı. Ankara, 2004.

24. Alberts HF. Tooth colored restoratives cototi. Alto, Boks. 1985: 31-2.

25. Dr. Philips Ed Practises.(www.cosmetic dentistryto. com)
26. Estetik / Gülüşün değerlendirilmesinde temel prensipler. (www.dentart.com)

27. Gürel G. Porselen Laminate Venerler Bilim ve Sanatı. Quintessence. 2004.

28. Nikgoo A, Alavi K, Alavi K, Mitfazaelian A. Assessment of the golden ratio in pleasing smiles. World J Orthodontics 2009;10:224-8.

29. Kalaivani S, Manochar J, Shakunthala P, Sujatha S, Rajasekaran SA, Karthikeyan B, Kalaiselvan S. Crown lengthening produce in the management of amelogenesis imperfecta. J Pharmacy \& Bioallied Sciences 2015; Suppl 7:769-72.

30. Mesaros A, Cornea D, Cioara L, Dudea D, Measaros M, Badea M. Facial attractiveness assessment using illustrated questionnairers. Clujul Med 2015;88:73-80.

31. Hasanreisoglu U, Berksun S, Aras K, Arslan I. An analysis of maxillary anterior teeth: facial and dental proportions. J Prosthet Dent 2005;94:530-7.

32. Condon M, Bready M, Quinn F, O'Connell BC, Houston FJ, O'Sullivan M. Maxillary anterior tooth dimensions and proportions in an Irish young adult population. J Oral Rehabilit 2011;38:501-8.

33. Preston JD. The golden proportion revisited. J Esthet Dent 1993;5:247-51.

34. Gillen RJ, Schwartz RS, Hilton TJ, et al. An analysis of selected normative tooth proportion. Int J Prosthodont 1994;7:410-7.

35. Rosential SF, Ward DH, Rashid RG. Dentist's preferences of anterior tooth proportion-a Webbased study. J Prosthodont 2009;9:123-36.

36. Al-Marzok MI, Majeed KRA, Ibrahim IK. Evaluation of maxillary anterior teeth and their relation to the golden proportion in malaysian population. BMC Oral Health 2013;13:9.

37. Koca G, Dinçkal N. Maksiller ve mandibular ön grup dişlerin boyutsal oranları. Ege Diş Hek Derg 1996; 17:1-3.

\section{Yazışma Adresi:}

Yrd. Doç. Dr. Hatice ÖZDEMİR

Atatürk Üniversitesi

Diş Hekimliği Fakültesi

Protetik Diş Tedavisi Anabilimdalı

Yakutiye/ERZURUM

(0 442) 2311783

dentist_hatice@hotmail.com 